University of San Diego

Digital USD

Spring 5-21-2016

\title{
Utilizing an Electronic Health Record Prompt to Improve Routine Tobacco Intervention in Student Health: An EBP Project
}

\author{
Molly Patricia Hurda \\ University of San Diego, mollyhurda@sandiego.edu
}

Follow this and additional works at: https://digital.sandiego.edu/dnp

Part of the Community Health and Preventive Medicine Commons, and the Health Information Technology Commons

\section{Digital USD Citation}

Hurda, Molly Patricia, "Utilizing an Electronic Health Record Prompt to Improve Routine Tobacco Intervention in Student Health: An EBP Project" (2016). Doctor of Nursing Practice Final Manuscripts. 19. https://digital.sandiego.edu/dnp/19

This Doctor of Nursing Practice Final Manuscript is brought to you for free and open access by the Theses and Dissertations at Digital USD. It has been accepted for inclusion in Doctor of Nursing Practice Final Manuscripts by an authorized administrator of Digital USD. For more information, please contact digital@sandiego.edu. 


\title{
UNIVERSITY OF SAN DIEGO
}

Hahn School of Nursing and Health Science

\section{DOCTOR OF NURSING PRACTICE PORTFOLIO \\ by \\ Molly Hurda, BSN}

\begin{abstract}
A portfolio presented to the
FACULTY OF THE HAHN SCHOOL OF NURSING AND HEALTH SCIENCE UNIVERSITY OF SAN DIEGO

In partial fulfillment of the

requirements for the degree

DOCTOR OF NURSING PRACTICE

May/2016
\end{abstract}


Final Manuscript

Utilizing an Electronic Health Record Prompt to Improve Routine Tobacco Intervention in Student Health: An EBP Project

\author{
Molly Hurda, DNP \\ mollyhurda@sandiego.edu
}




\begin{abstract}
Purpose: Improve the use of tobacco screening and cessation interventions by utilizing an Electronic Health Record (EHR) prompt in a university student health center.

Background: It is well known that the leading cause of preventable morbidity and mortality in the United States (US) is the use of tobacco products. Tobacco use accounts for $\$ 289$ billion in direct health care costs and loss of productivity annually. Nearly all smokers (98 percent) start before 26 years of age making college campuses an important area for tobacco intervention. ${ }^{1}$ A southern California university recently adopted a comprehensive tobacco-free campus policy that prohibits the use of smoking and tobacco use on all campus property. In conjunction with a comprehensive policy, offering cessation assistance to tobacco users maximizes the impact of the policy.,3
\end{abstract}

Practice Change: Two mandatory EHR prompts were created for tobacco screening and alerting the provider to intervene if screening was positive.

Outcomes: Screening for tobacco use increased from $89 \%$ to $99.5 \%$ for all students visiting the student health center. The percentage of patients offered tobacco cessation resources increased from $15 \%$ to $47 \%$. The overall percentage of students receiving any intervention beyond screening increased from $65 \%$ to $81 \%$.

Conclusions: This evidenced-based practice project resulted in an increase in the identification of tobacco users and an increase in tobacco cessation interventions by providers. 


\section{Background}

It is well known that the leading cause of preventable morbidity and mortality in the US is the use of tobacco products. Tobacco use accounts for $\$ 289$ billion in direct health care costs and loss of productivity annually. Nearly all smokers (98 percent) start before 26 years of age making college campuses an important area for tobacco intervention. ${ }^{1}$ A southern California university recently adopted a comprehensive tobacco-free campus policy that prohibits the use of smoking and tobacco use on all property both indoors and outdoors. In conjunction with a comprehensive policy, offering cessation assistance to tobacco users maximizes the impact of the policy. The benefit of population-level tobacco control measures is augmented by offering accessible and effective tobacco treatments. ${ }^{2-3}$ The Centers for Disease Control and Prevention's (CDC) Best Practices for Comprehensive Tobacco Control Programs recommend system changes that make tobacco intervention a part of every patient encounter by integrating this into the clinic workflow. ${ }^{3}$

\section{Purpose}

The campus clinic was screening for tobacco use at patient visits, but this was not occurring consistently and pre-data revealed $89 \%$ of patients were being screened. For those patients who screened positive for tobacco use, there was a tobacco intervention template that was to be added to the patient's electronic record, but it was a cumbersome process and required several extra steps for the medical assistant (MA) or registered nurse (RN) to add it into the EHR. The tobacco template was being added $74 \%$ of the time. The aim of this evidence-based practice (EBP) project was to improve the use of tobacco screening by making this a required field in the EHR and to increase consistent 
tobacco intervention of clinicians by utilizing an automatic EHR prompt. The Clinical Practice Guideline for Tobacco Use and Dependence recommend using the "5 As" model for routine tobacco intervention. The 5 A's are as follows: ask every patient about tobacco use and document in their record at every visit, advise every tobacco user to quit, assess the patient's willingness to quit, assist the willing patient to quit by offering medication and/or providing or referring for counseling, and arrange for follow-up. ${ }^{2}$ When pre-data was evaluated $65 \%$ of the patients who screened positive for tobacco use, had any of these interventions beyond screening documented.

The American College Health Association (ACHA) tobacco guideline not only recommends a comprehensive tobacco policy like the one recently adopted on campus, but also recommends that the campus promote and have accessible cessation services to the campus community. ${ }^{4}$ In conjunction with the campus efforts to implement the policy, the university's counseling center and clinic had increased efforts to promote their cessation services to the campus community. The EHR changes reflected in this paper were part of a larger effort to fight tobacco use on a college campus.

\section{Synthesis of the Evidence}

The CDC's Best Practices for Comprehensive Tobacco Control Programs recommend system changes that make tobacco intervention a part of every patient encounter by integrating this into the clinic workflow. ${ }^{3}$ Evidence supports routine clinical intervention of documenting tobacco use status, advising cessation and assessing the patient's willingness along with providing evidence-based cessation treatments or referral for treatment. ${ }^{2,3,5,6}$ Specifically, EHRs have been supported as useful tools to facilitate this process. ${ }^{3,7-13}$ 
The impact of having a system in place for identifying tobacco users is shown in a meta-analysis of 9 studies. It revealed that clinicians are more than 3 times as likely to provide intervention when routine identification and documentation of tobacco users occurs. $^{2}$ The evidence supporting the use of EHR prompts as a clinical reminder for clinicians to provide tobacco intervention is growing. A systematic review of 16 studies looked at the use of prompts on the various aspects of the 5A's and increases in all aspects of the tobacco intervention to include ask, advise, assess, assist and refer were demonstrated. ${ }^{9}$

To reiterate the importance of the 5A's as an effective intervention a metaanalysis of 7 studies and a systematic review of 17 trials showed similar results that brief advice to quit led to an increase in cessation by $1-3 \% .^{2,14}$ If you go on to offer counseling and medication, the impact becomes greater, reaching abstinence rates up to $27.6 \%$ when combined. ${ }^{2}$ Considering the evidence and guideline recommendations, the decision was made to incorporate this at the student health center.

\section{Practice Change}

In order to increase tobacco screening and routine tobacco intervention by providers, two changes were made to the EHR in the student health center. First, a tobacco screening template was created and designated as a mandatory field. This template was then associated with initial patient intake data along with vital signs and chief complaint. The medical assistant or nurse did have the option to select unable to assess if emergency situations arose where it would not be appropriate to screen for tobacco use. Second, a new mandatory tobacco cessation intervention template was created in the EHR that prompted the provider to intervene. If the patient screened 
positive for tobacco use, this new template was automatically added to the note without any extra steps. This prompt alerts the provider to advise the student to quit, assess readiness for change, discuss negative health consequences of tobacco use and discuss and/or refer to cessation resources and medications. The changes that were made to the EHR were evaluated for patient visits scheduled to see a provider. Data was not collected from nurse only visits and visits for immunizations.

\section{Implementation}

This practice change occurred on September 2, 2015. One-on-one staff training was provided on the new template this same day. The post-data was collected starting the day of implementation, September 2, 2015 through January 2, 2016. The pre-data was collected for the time period of September 2, 2014 to January 2, 2015 in order for the best comparison. The project was submitted through the campus institutional review board (IRB) and approval was obtained under exempt status on September 29, 2015.

The affected staff included 5 providers, 3 MAs and 3 RNs. Being such a small group, it was easy to conduct individual staff training. The support of the clinic director and supervising physician was vital to the success of the change and these two key personnel were important champions. The Iowa Model of EBP was used as the implementation guide.

\section{Outcomes}

EHR data was utilized to evaluate the effectiveness of the project. The EHR prompt to incorporate the tobacco template automatically increased the percentage of times that the tobacco template was added to the chart of those patients who screened 
positive for tobacco use from $74 \%$ to $100 \%$. No longer relying on a person to add the template into the note made a significant difference.

Table 1 compares pre-intervention data with the results of the post-intervention data resulting from the tobacco screening and intervention EHR prompts. Areas that showed a substantial increase were the percentage of patients asked about tobacco use (increased from $89 \%$ to $99.5 \%$ ), the percentage of patients who were offered or had a discussion about available resources (increased from 15\% to 47\%) and the overall percentage of students that had any intervention beyond screening (increased from 65\% to $81 \%$ ). There was a $2 \%$ decrease in the patients advised to quit and no change in those that had their willingness to quit assessed.

Table 1. Tobacco Intervention Pre and Post-EHR Change

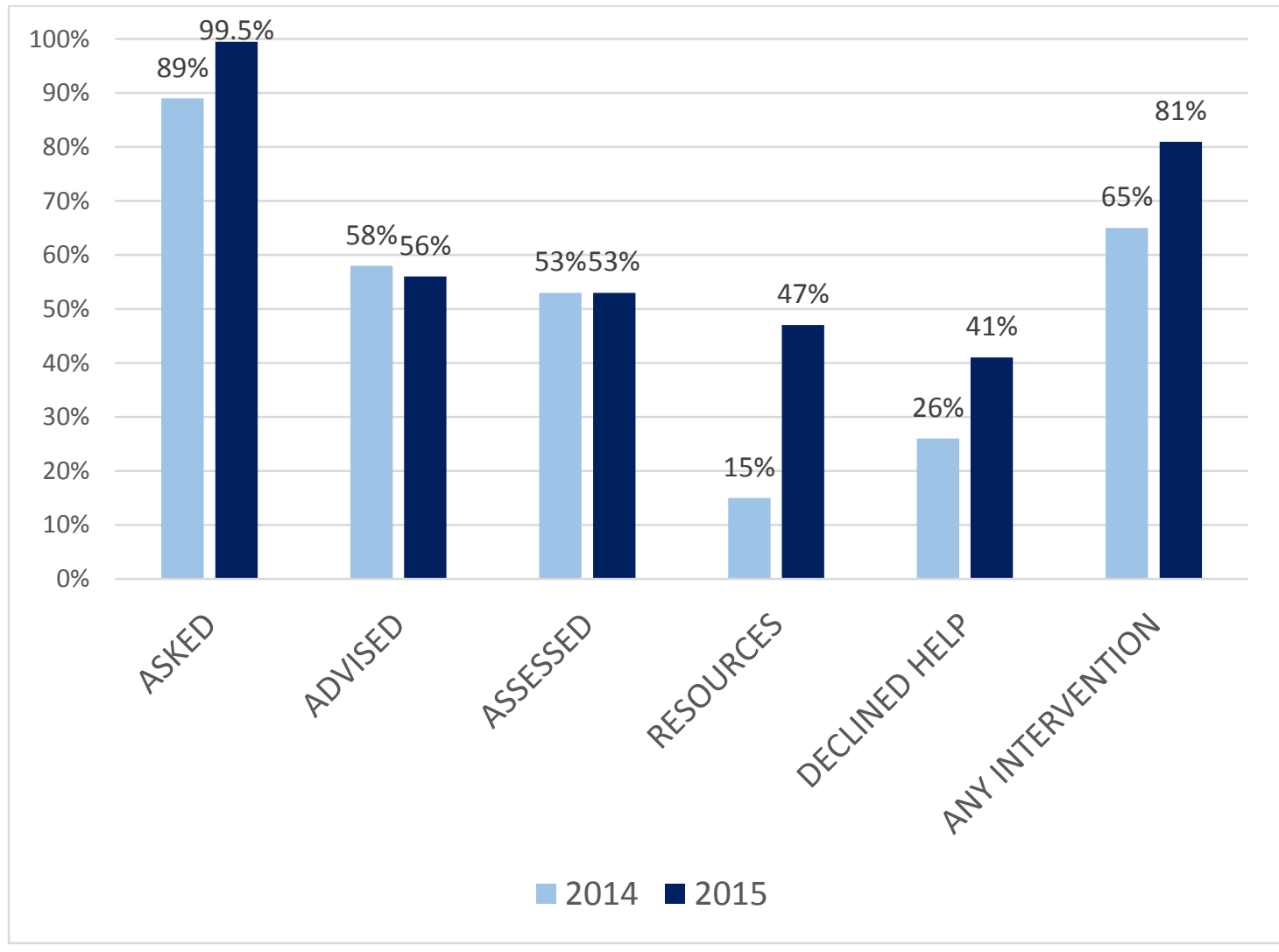


The jump to nearly $100 \%$ screening reflects the success of changing the tobacco use field to a mandatory field. Out of 2143 patient encounters in the post-data collection time period, 2133 were screened and 10 were documented as unable to assess. The increase in patients being offered resources not only reflects that the automatic prompt improved routine intervention by providers, but reflects the increased campus efforts to make tobacco cessation resources more accessible. The university's counseling center expanded their services to offer tobacco cessation counseling. Having this resource on campus was important for both the students and providers. It is a free, accessible resource for interested students.

Table 2 reflects the pre and post data in a control chart. It reflects a 6 week statistically significant trend in the weeks following the EHR changes. A downward trend was then noticed and is thought to be partially due to some providers that started to document, "previously discussed" in the patient's EHR instead of addressing the tobacco use. The trend started the third week in October after the fall semester was well underway. At this point in the semester, some of the same students are returning for repeat visits and several of them had just previously had a discussion about their tobacco use with the provider. This in turn affected the data. 
Table 2. Impact of EHR Prompt on Tobacco Intervention for Tobacco Users

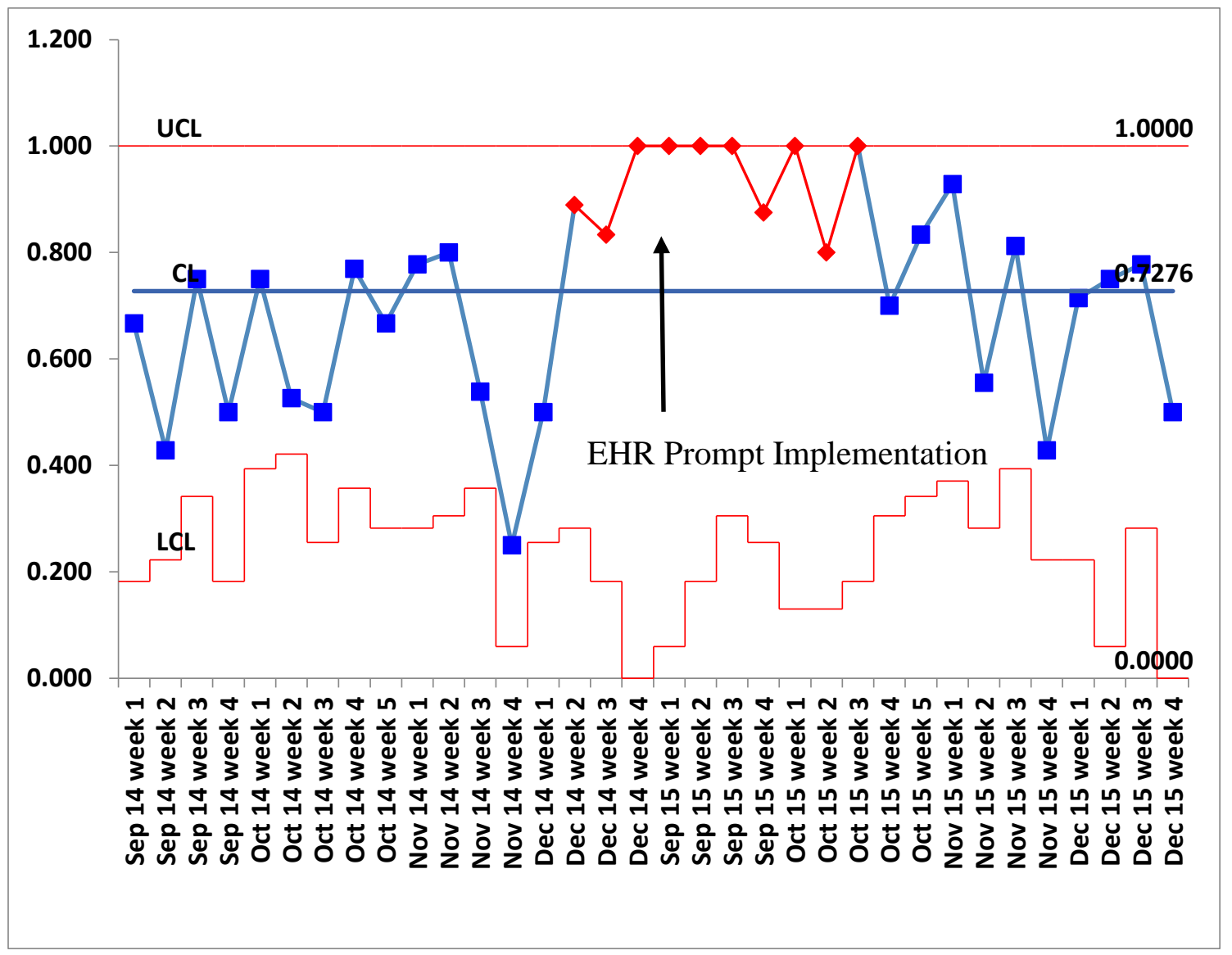

Note. Red dots indicate statistically significant change

\section{Implications for practice}

After project implementation and data analysis, there are several implications for clinical practice. First, it is important to clarify what is the expectation of the provider to intervene if tobacco was just recently addressed with a student. Clarifying what recently means as well would be important: is it 1 week, 1 month; or is the expectation that regardless if the patient was just seen the day before, tobacco intervention is provided at every visit, as recommended in the guideline. ${ }^{2}$ Having this worked out prior to the EHR change would have been helpful. 
The next step, particularly at this clinic, would be to expand the focus on all clinic appointment types and not just the provider visits. Studies have shown that tobacco cessation advice and counseling is similarly effective amongst multiple health care professionals to include not only physicians, nurse practitioners and physician assistants, but nurses as well. ${ }^{2}$

Lastly, it would be interesting to track referrals and cessation rates. This was not part of the project or data collection, but would provide additional information on the success of the project and the campus efforts in general to fight tobacco use amongst this population.

\section{Conclusions}

This EBP project met its intended aims: to increase the identification of tobacco users and to increase the intervention of tobacco users by utilizing the functions of an EHR. The results are consistent with the evidence that shows system changes are an effective way to increase tobacco screening and intervention. The changes made are a sustainable addition to the routine care offered at this clinic and a complement to the comprehensive tobacco-free campus policy. The efforts on this southern California university are in support of the ACHA tobacco guideline and Healthy Campus 2020 tobacco use goals. ${ }^{4,16}$ 


\section{References}

1. US Department of Health and Human Services. The Health Consequences of Smoking50 Years of Progress: A Report of the Surgeon General. Atlanta, GA: US Department of Health and Human Services, Centers for Disease Control and Prevention, National Center for Chronic Disease Prevention and Health Promotion, Office on Smoking and Health; 2014.

2. Fiore MC, Jaen CR, Baker TB, et al. Treating Tobacco Use and Dependence: 2008 Update. Clinical Practice Guideline. Rockville, MD: US Department of Health and Human Services. Public Health Service. May 2008.

3. Centers for Disease Control and Prevention. Best Practices for Comprehensive Tobacco Control Programs-2014. Atlanta, GA: US Department of Health and Human Services, Centers for Disease Control and Prevention, National Center for Chronic Disease Prevention and Health Promotion, Office on Smoking and Health, 2014.

4. American College Health Association. Position statement on tobacco on college and university campuses. J Am Coll Health. 2012; 60(3): 266-267.

doi:10.1080/07448481.2012.660440

5. Tobacco Free Initiative (TFI). World Health Organization Web site. http://www.who.int/tobacco/control/health_professionals/en/index3.html\# Accessed February 28, 2016.

6. Agency for Healthcare Research and Quality. Systems Change: Treating Tobacco Use and Dependence. http://www.ahrq.gov/professionals/clinicians- 
providers/guidelines-recommendations/tobacco/decisionmakers/systems/index.html Published December 2012. Accessed August 22, 2015.

7. Silfen SL, Farley SM, Shih SC, et al. Increases in smoking cessation interventions after a feedback and improvement initiative using electronic health records -19 community health centers, New York City, October 2010-March 2012. MMWR. 2014;63(41):921-924.

8. Land TG, Rigotti NA, Levy DE, Schilling T, Warner D, Li W. The effect of systematic clinical interventions with cigarette smoker on quit status and the rates of smoking-related primary care office visits. PLoS One 2012;7:e41649. doi:10.1371/journal.pone.0041649.

9. Boyle R, Solberg L, Fiore M. Use of electronic health records to support smoking cessation. Cochrane Database Syst Rev. 2014;12:1-32. doi:10.1002/14651858.CD008743.pub3.

10. Greenwood DA, Parise CA, MacAller TA, et al. Utilizing clinical support staff and electronic health records to increase tobacco use documentation and referrals to a states quitline. $J$ Vasc Nurs. 2012;30:107-11. doi:10.1016/j.jvn.2012.04.001.

11. Bentz CJ, Bayley KB, Bonin KE, et al. Provider feedback to improve 5A's tobacco cessation in primary care: a cluster randomized clinical trial. Nicotine Tob Res. 2007;9:341-349. doi:10.1080/14622200701188828.

12. Lindholm C, Adsit R, Bain P, et al. A demonstration project for using the electronic health record to identify and treat tobacco users. WMJ. 2010;109(6):335-340. 
13. Linder JA, Rigotti NA, Schneider LI, Kelley JHK, Brawarsky P, Haas J. An electronic health record-based intervention to improve tobacco treatment in primary care. Arch Intern Med. 2009; 169(8):781-787.

14. Stead LF, Buitrago D, Preciado N, Sanchez G, Hartmann-Boyce J, Lancaster T. Physician advice for smoking cessation (review). Cochrane Database Sys Rev. 2013;5:1-75. doi:10.1002/14651858.CD008743.pub3.

15. World Health Organization. WHO Report on the Global Tobacco Epidemic, 2008: The MPOWER package. Geneva: World Health Organization, 2008.

16. American College Health Association. Healthy Campus 2020 - Student Objectives. https://www.acha.org/healthycampus. Published June 2012. Accessed March 5, 2016. 